\title{
OUT-OF-PLANE SEISMIC RESPONSE OF MASONRY FAÇADES USING DISCRETE MACRO-ELEMENT AND RIGID BLOCK MODELS
}

\author{
L. Giresini ${ }^{1 *}$, B. Pantò ${ }^{2}$, S. Caddemi ${ }^{2}$ and I. Caliò ${ }^{2}$ \\ ${ }^{1}$ Department of Energy, Systems, Territory and Constructions Engineering, University of Pisa, \\ Largo Lucio Lazzarino, 1, 56100, Pisa, Italy; linda.giresini@unipi.it. \\ ${ }^{2}$ Department of Civil Engineering and Architecture, University of Catania, Via S. Sofia 64, 95125 \\ Catania, Italy \\ e-mail: \{bpanto, scaddemi, icalio\}@ dica.unict.it
}

*Presenting author

\begin{abstract}
This paper investigates the out-of-plane response of masonry façades under earthquakes by means of two different approaches. A discrete macro-element approach, based on modelling the structure by means of spatial deformable macro-elements interacting through nonlinear zero-thickness interfaces, and the classical approach in which the masonry façade is assumed as a rigid block subjected to earthquake loading. The latter method neglects the elasticity of the masonry element and contemplates the energy dissipation only at each impact by means of a coefficient of restitution. The results of dynamic non-linear analyses, performed with the two methods on a real case of a church façade, provide a first comparison between the two approaches highlighting some limits of application of the simplified rigid block model.
\end{abstract}

Keywords: rocking, discrete macro-element, rigid block, historic masonry, masonry façade. 


\section{INTRODUCTION}

The dynamic response of masonry monumental buildings subjected to earthquake excitations is governed by the in-plane and out-of-plane response of masonry walls. When the connections between walls or, more in general, between vertical and horizontal structural elements do not guarantee a box-type behavior, the out-of-plane failure mechanisms represent the main source of seismic vulnerability of the building. Irregular buildings, where torsional modes increase the seismic demand in specific parts, are also vulnerable to out of plane modes [1][2]. Simplified models [3] generally do not account for the in and out-plane behavior in a unique numerical model, being based on numerical strategies that accounts for in-plane walls behavior only. In these cases, the out of plane response is generally taken into account by limit or nonlinear dynamic analyses in which the walls is regarded as set of rigid block structures rotating either around horizontal or vertical axis (in case of simple cantilever or flexural bending mechanisms) or identifying structural portion characterized by a more complex kinematics [4].

The out-of-plane analysis of masonry walls can be performed by finite element or discrete element numerical models or using limit analysis approaches. These latter approaches are often based on the Heyman's assumptions [5], realistic for masonry elements behaving out of plane: rigid blocks of infinite compressive strength, joints with null tensile strength and absence of sliding failures. The rocking capacity is evaluated by considering force-based or displacementbased criteria. Among the force-based approaches, the static analysis is the most straightforward and easiest tool to assess the seismic force capacity of rocking rigid blocks (e.g. for historic walls [6]). The displacement based approaches consist in analyzing the evolution of the seismic force in relationship with the displacement of a control point, generally chosen as the center of mass of the rigid element. The force-displacement law, which can be obtained by the principle of virtual work, is comparable to a push-over curve expressing the total base force in horizontal direction against the displacement. The seismic capacity is generally obtained as a fraction of the displacement corresponding to the acceleration capacity, whereas the seismic demand is taken from the acceleration-demand response spectrum with the definition of a secant period [7].

Another analysis method that can be compared to force-based and displacement-based approaches is the non-linear dynamic analysis of rigid blocks. This differs from the former for considering the evolution of motion over time. In addition, it takes into account energy dissipation, issue of primary importance in the seismic analysis of structural elements. The comparison between displacement based, force based and rocking approaches was discussed in previous works, e.g. in [7].

Recently, a discrete macro-element method (DMEM) able to account for the in and the outof-plane behavior of a masonry structures has been proposed. This innovative strategy has been initially presented and validated in the nonlinear static field [8][9], and more recently has been extended in the dynamic field and validated through the comparison with experimental tests and refined finite element simulations [10][11]. According to the DMEM, a masonry façade is discretized as a mesh of shear deformable spatial macro-elements interacting through zerothickness interfaces. The basic macro-element possesses a shear-plane deformability governed by a single degree of freedom and interacts with the adjacent macro-element by means of $2 \mathrm{D}$ interfaces whose discretization follows a straightforward fiber calibration strategy, more detail on the DMEM can be found in the previous referenced papers.

The capability of the proposed DMEM to account for the in and out-of-plane behavior of masonry structure has been already numerically and experimentally investigated [12][13]. In this paper the DMEM method is applied for evaluating the nonlinear dynamic response of a 
typical church façade subjected to earthquake loadings. The influence of the masonry deformability and the role of the dissipation are considered in the different implemented models. Furthermore, the DMEM results are compared with those obtained by applying the simplified rigid rocking $(R R)$ approach, being the strategy generally adopted and suggested by several technical codes.

\section{THE ADOPTED NUMERICAL MODELS}

Two different approaches have been adopted for simulating the out-of-plane seismic response of a typical façade of a masonry church: the Discrete Macro-Element Model (DMEM) and the Rigid block Rocking $(R R)$ approach. The first model considers the masonry deformability and allow to account for energy dissipation by introducing a viscous damping matrix, whereas the latter takes into account the energy dissipation related to the impacts between rigid body through assumed values of the coefficient of restitution.

\subsection{The approach based on the dynamic of the rigid block}

In the $R R$ approach the masonry wall is assumed as a rigid prismatic block subjected to earthquake loading. The nonlinear equation of motion [14] can be written as follows:

$$
I_{0} \ddot{\vartheta}+\operatorname{sgn}(\vartheta) m g R \sin (\alpha-\operatorname{sgn}(\vartheta) \vartheta)-m \ddot{u}_{g} R \cos (\alpha-\operatorname{sgn}(\vartheta) \vartheta)=0
$$

where the rotation $\vartheta$ ( $>0$ if counter-clockwise) has been assumed as the Lagrangian coordinate. In Eq. (1), $\alpha$ is the slenderness ratio (arctangent of ratio thickness to height, Figure 1), $I_{0}$ is the inertia moment, $m$ the mass and $\ddot{u}_{g}$ the ground acceleration. Several experimental and numerical investigations had shown that the actual behavior of structures whose earthquake response is dominated by rigid rocking is characterized by strong nonlinearities and cannot be fully predicted. Very small variations in the geometry, support conditions, damping properties and the actual elasticity of the block lead to different time histories [9]. In the theoretical model here considered the block is considered rigid and the dissipation of energy occurs at each impact of the block on its base according to a constant restitution coefficient. According to the Housner's formulation, the expression of the coefficient of restitution $e_{a n}$ is assumed as [14]:

$$
e_{a n}=1-\frac{3}{2} \sin ^{2} \alpha
$$

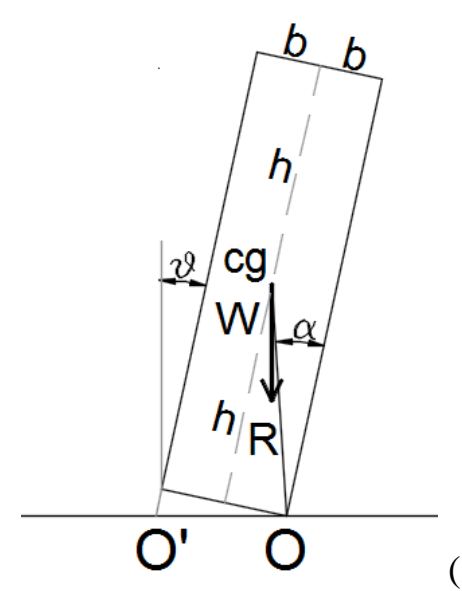

(a)

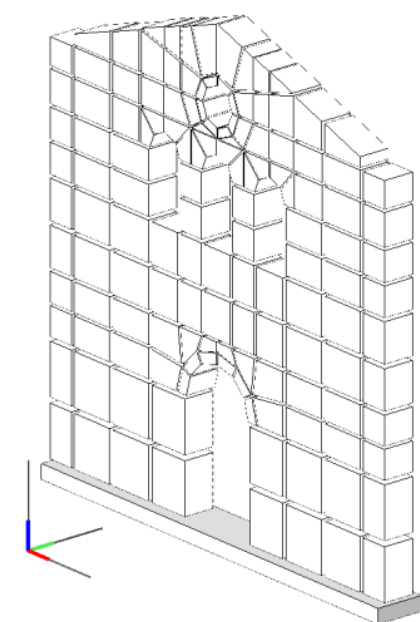

(b)

Figure 1: The rocking rigid model (RR, a) and the discrete macro-element (DME, b) model. 
The analytical value of the coefficient of restitution given by Eq. (2) was generally found to be greater than the experimental one in tests of masonry specimens [15]. By recognizing the difficulty in correlating the coefficient of restitution with the maximum rotation before impact or with the semi-period, Sorrentino et al. [15] suggested a realistic value of $e$ equal to $95 \%$ of the analytical value for fired clay and tuff brickwork. In addition, Giresini et al. [16] proposed to assume $85 \%$ of the analytical value for rubble masonry. In this paper two values of $90 \%$ and $95 \%$ have been adopted in the numerical investigations.

\subsection{The adopted Discrete Macro-Element Method}

In the adopted DMEM, the masonry façade is discretized according to a mesh of macroelements, Figure 1b. Each macro-elements governs the shear deformability while the flexural torsional and shear-sliding behavior are governed by the zero-thickness interfaces connecting the elements [9]. The basic element can be regarded as an articulated quadrilateral interacting to the other elements and the external supports by non-linear interfaces (Figure 2a) calibrated according to a fiber approach in which the nonlinear constitutive law of each fiber can be attributed to a corresponding nonlinear link. The kinematics of each macro-element is governed by seven degrees of freedom only, able to describe the rigid body motions plus the element inplane shear deformability. The axial/flexural behavior is governed by $m$ rows of $n$ transversal non-linear links which rule the coupled in-plane and out-of-plane masonry axial/flexural behavior (Figure 2b). The in-plane sliding motion between two continuous elements is governed by a single longitudinal in-plane nonlinear link and two additional links oriented orthogonally to the plane of the element (Figure 2c). The latter two additional springs govern both the out-of-plane sliding mechanisms and the torsion around the axis perpendicular to the plane of the interface. The non-linear Links are calibrated assuming that the masonry is a homogeneous non-linear material. Elastic, linear softening constitutive laws with different strength and displacement capacity in tension and compression simulate the masonry flexural behavior while, diagonal Links are calibrated according to the Mohr Coulomb criterion. A detailed description of the DMEM and its calibration strategies can be found in [8][9] and [17] [19].

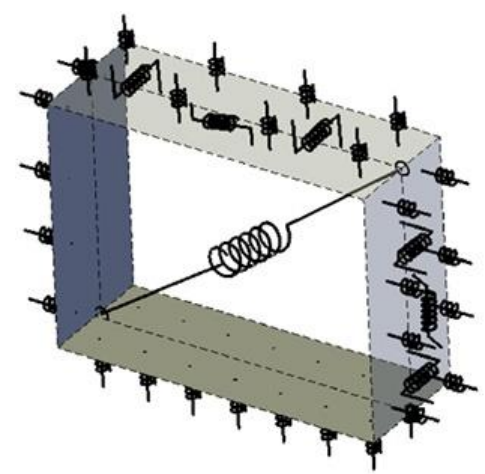

(a)

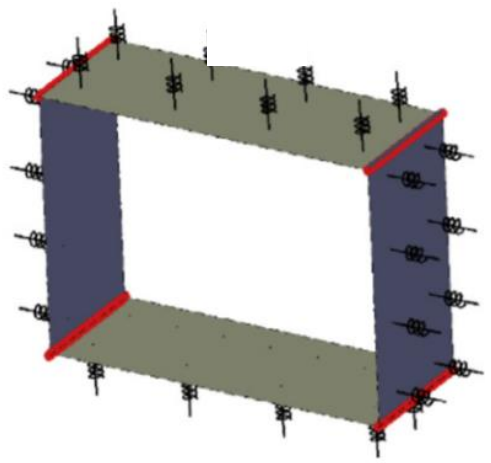

(b)

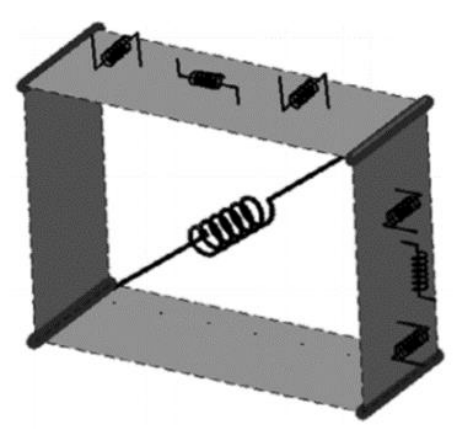

(c)

Figure 2: Mechanical scheme of the discrete macro-model: 2D in-plane model (a); 3D model (b,c).

The DMEM has been employed to simulate the seismic behavior of monumental masonry constructions by means of non-linear static (push-over) analyses [20][21]. Recently, the model has been extended to the dynamic field [12].

With regard to the energy dissipation, the DME model includes two sources of dissipations: the non-linear hysteresis of the material (tensile cracking, compression crashing and diagonal-shear yielding), and an additional viscous Rayleigh damping governed by a global damping matrix:

$$
C=a_{0} K+a_{1} M
$$


proportional to the global initial stiffness $(K)$ and mass $(M)$ matrices of the system. With the aim to assume a comparable energy dissipation in the two models, the following expression (4), that relate the coefficient of restitution e to an equivalent viscous damping coefficient $\xi$ [22] is be used. The main differences between the two modeling approach are summarized in the following Table 1.

$$
\xi=\frac{2(1-e)}{\pi(1+e)}
$$

Table 1: Main differences between the two adopted approaches.

\begin{tabular}{lccc}
\hline Method & Model & Elasticity & Energy dissipation \\
\hline DMEM & $\begin{array}{c}\text { Elastic - rotation hinge not } \\
\text { defined } \text { a priori } \\
\text { Rigid block - horizontal } \\
\text { hinge at the ground }\end{array}$ & $\begin{array}{c}\text { Encountered - } \\
\text { variable elastic modulus } \\
\text { Neglected - fully rigid block }\end{array}$ & Rayleigh damping \\
& & & \\
& Coefficient of restitution \\
\hline
\end{tabular}

\section{THE CASE STUDY: SAN MICHELE CHURCH}

Most historical masonry buildings suffered heavy damage during the 2017-2018 earthquake swarm of the Central Italy. The incipient out-of-plane of the main façade of churches represented a recurrent damage scenario. The out-of-plane mode was triggered by the strong component of the earthquake acceleration in north-south direction, particularly in presence of poor connection between the main façade and the transversal walls and between the barrel vault and façade, as often occurs in historic churches [23][24].

In this paper the case of San Michele church (Figure 3) located in central Italy, that exhibited an incipient out-of-plane response of the main façade, is investigated.

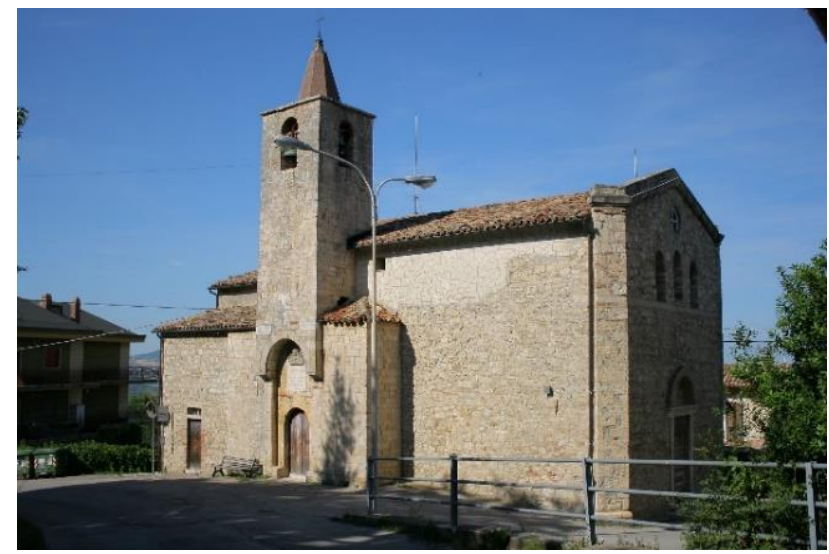

(a)

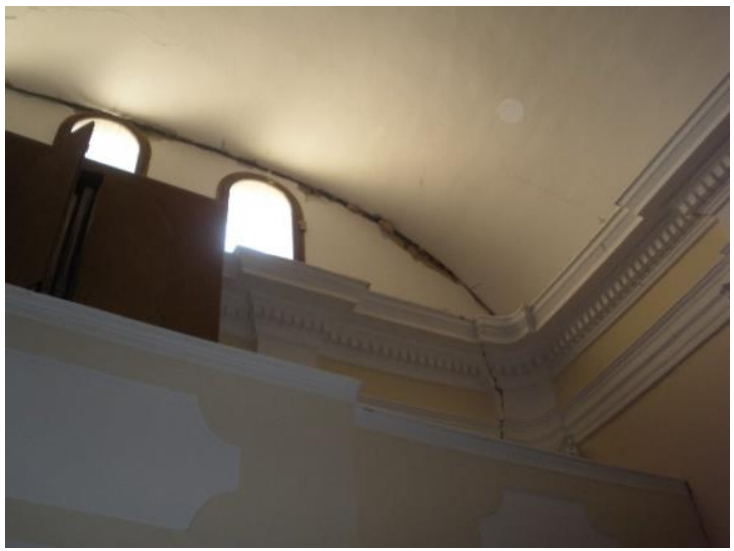

(b)

Figure 3: San Michele church: global view (a); incipient out-of-plane mechanism of the façade, view from inside the building (b).

\subsection{Geometry and mechanical features}

The single nave church has a regular rectangular plan $(10 \mathrm{~m}$ x $20 \mathrm{~m})$, with a bell tower located in one side of the church and structural integrated to the building (Figure 3a). The façade is $9.30 \mathrm{~m}$ wide and $9.70 \mathrm{~m}$ high with a volume is $48 \mathrm{~m}^{3}$. Its slenderness ratio $\alpha$ is about 0.07 , obtained as the arctangent of the ratio height of half-thickness and the depth of center of mass $(0.325 \mathrm{~m} / 4.545 \mathrm{~m}$, Figure 4). More details on the features of the church can be found in [22]. Since no experimental data are available, the masonry mechanical parameters have been estimated from a qualitative survey of the external masonry texture (Figure 3a). 


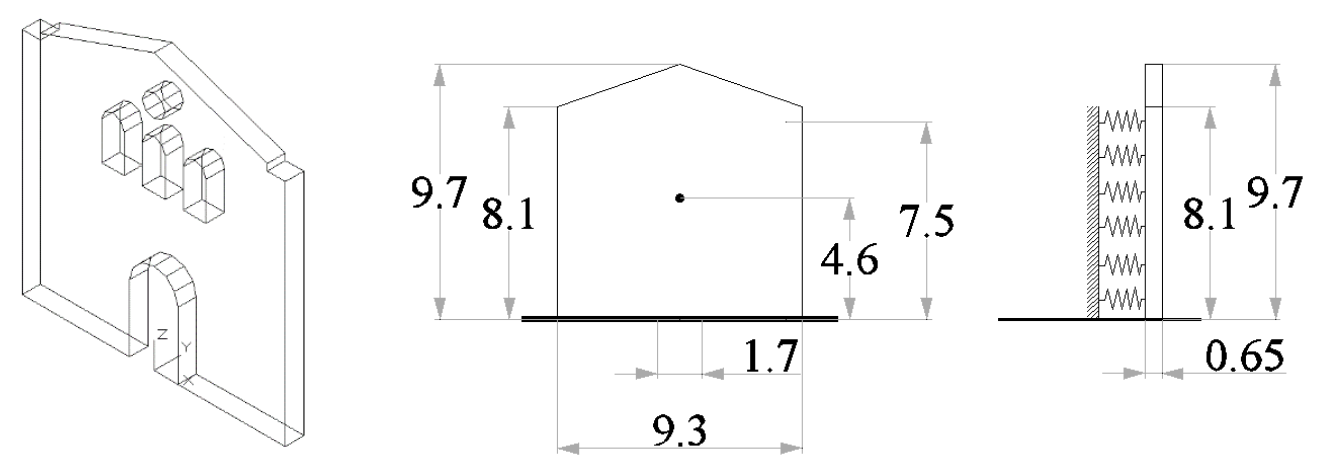

Figure 4: Geometrical features of the main façade (units in $\mathrm{m}$ ).

The masonry has been assimilated to a medium quality masonry of irregular stones, according to the classification reported in the Italian technical code [25] with a unit weight $w=20$ $\mathrm{kN} / \mathrm{m}^{3}$. The assumed material properties suggested by the code in terms of elastic modulus $(E)$, tangential modulus $(G)$, compression strength $\left(f_{c}\right)$, shear strength in absence of axial load $\left(f_{v 0}\right)$ are reported in Table 2 . The tensile strength $\left(f_{t}\right)$ and tensile ductility capacity $\left(\mu_{t}\right)$ are assumed to be representative of a low quality mortar joints.

A perfectly plastic behavior has been assumed for compression and a $0.4 \%$ ultimate drift for the in-plane diagonal-shear mechanism has been adopted.

Table 2: Mechanical masonry parameters adopted in the analyses.

\begin{tabular}{ccccccccc}
\hline \multicolumn{4}{c}{ Flexural behavior } & \multicolumn{4}{c}{ Diagonal shear behavior } \\
\hline$w$ & $E$ & $f_{c}$ & $f_{t}$ & $\mu_{\mathrm{t}}$ & $\mu_{\mathrm{c}}$ & $G$ & $f_{v o}$ & $\gamma_{\mathrm{u}}$ \\
$\left(k N / m^{3}\right)$ & $(M P a)$ & $(M P a)$ & $(M P a)$ & $(-)$ & $(-)$ & $(M P a)$ & $(M P a)$ & $(\%)$ \\
\hline 20 & 1500 & 2.6 & 0.001 & 2.0 & unlimited & 500 & 0.056 & 0.4 \\
\hline
\end{tabular}

\subsection{Selection of earthquake inputs}

The earthquakes selected for the numerical analyses are those recorded in the 2016-2017 Central Italy earthquake and available from the Engineering Strong Motion database [22]. Namely the events characterized by the highest PGA, PGV and PGV/PGA have been considered. The PGV represents one of the most relevant Intensity Measures (IM) that has to be considered in the rocking analysis of out-of-plane modes, however also other velocity and energy based IMs can assume a certain relevance [22]. The considered accelerograms and the corresponding IMs are reported in Table 3. AMT and T1213 have the highest PGA, together with high PGV values, whereas NOR has the highest PGV/PGA ratio. The corresponding records, in terms of accelerations, are displayed in Figure 5.

Table 3: Intensity Measures associated to the selected seismic records - Peak Ground Acceleration $(P G A)$, Velocity $(P G V)$, Displacement $(P G D)$, Housner's Intensity $\left(S I_{H}\right)$, Arias Intensity $\left(I_{a}\right)$, Energy Density $\left(I_{v}\right)$, Fajfar Index $\left(I_{F}\right)$.

\begin{tabular}{ccccccccc}
\hline $\begin{array}{c}\text { Accelerometric } \\
\text { stations }\end{array}$ & $\begin{array}{c}\text { PGA } \\
\left(\mathrm{cm} / \mathrm{s}^{2}\right)\end{array}$ & $\begin{array}{c}\text { PGV } \\
(\mathrm{cm} / \mathrm{s})\end{array}$ & $\begin{array}{c}\text { PGV/PGA } \\
(\mathrm{s})\end{array}$ & $\begin{array}{c}\mathrm{PGD} \\
(\mathrm{cm})\end{array}$ & $\begin{array}{c}\mathrm{SI}_{\mathrm{H}} \\
(\mathrm{cm})\end{array}$ & $\begin{array}{c}\mathrm{I}_{\mathrm{a}} \\
(\mathrm{cm} / \mathrm{s})\end{array}$ & $\begin{array}{c}\mathrm{I}_{\mathrm{v}} \\
\left(\mathrm{cm}^{2} / \mathrm{s}\right)\end{array}$ & $\begin{array}{c}\mathrm{I}_{\mathrm{F}} \\
\left(\mathrm{cm} / \mathrm{s}^{3 / 4}\right)\end{array}$ \\
\hline AMT & 521.62 & 37.91 & 0.07 & 6.02 & 90.41 & 156.37 & 667.05 & 63.59 \\
NOR & 305.74 & 56.24 & 0.18 & 23.02 & 252.65 & 288.78 & 5522.98 & 109.94 \\
T1213 & 779.27 & 60.73 & 0.08 & 12.42 & 151.47 & 555.65 & 1432.70 & 139.84 \\
\hline
\end{tabular}



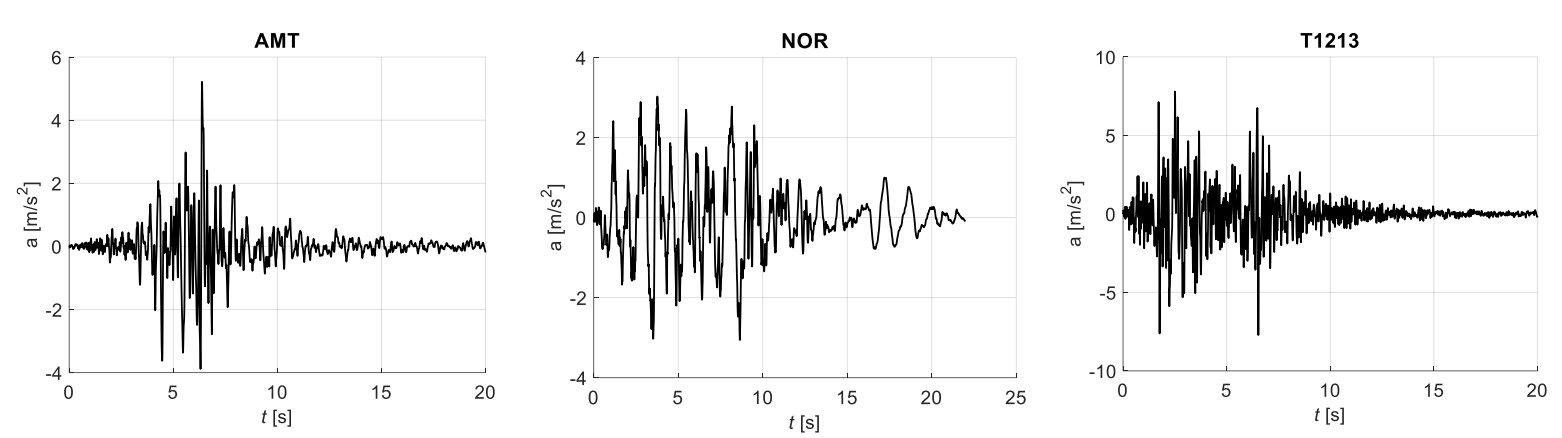

Figure 5: Seismic records used for the parametric analyses.

\section{RR AND DME MODELS}

In this section the out-of-plane response of façade is numerically investigated. The rigid block based numerical analyses are firstly performed considering a free-standing condition of the façade, denoted as 2-Sided motion (2S) model. In addition, a condition in which the façade interacts with the orthogonal walls, namely 1 -Sided motion $(1 S)$ model is considered. Aiming at evaluating the role of the masonry deformability all the results are compared with those obtained by considering the DMEM strategy.

\subsection{Rigid block based model analyses}

Table 4 reports the mechanical and geometrical needed parameters representing the rigid block based models. The equation of motion (Eq. 1) is solved step by step with a $5^{\text {th }}$ order Runge Kutta method considering first the façade as completely free-standing, and then taking into account a unilateral spring bed as boundary condition (Figure 4); the corresponding equation of motion is reported in [22]. A compressive bed spring $\left(K_{\text {compr }}\right)$ is considered in the onesided motion calculated as reported in [22], whereas an average tensile spring bed stiffness $\mathrm{K}_{t, m}^{\prime}$ has been assumed. This has been obtained by imposing and equivalence with a corresponding frictional macro-element model [26] for a displacement $d_{1}$ corresponding to the end of the constant friction force $F_{p, 1}$ in the capacity curve obtained from the kinematic analysis. The tensile spring bed stiffness $\mathrm{K}_{t, 1}^{\prime}$ is the ratio of the corresponding frictional force with respect to the displacement times the thickness of the transverse walls $s_{t}$, that is $\mathrm{K}_{t, 1}^{\prime}=F_{p, 1} / d_{1} s_{t}$ [26]. The geometrical parameter $Z g$ represents the height of the center of mass, $R$ is the radius vector, $h$ the equivalent block height, $\alpha$ the slenderness ratio of the block, $\rho$ the masonry density, $I_{0}$ the moment of inertia. These values are calculated with the expressions reported in [22]. The energy dissipation is taken into account considering initially $90 \%$ (for one-sided and two-sided motion) of the analytical coefficient of restitution (Eq. 2) and secondly $95 \%$ of this value (only for twosided motion).

Table 4: Mechanical and inertia features of the rocking block in the RR model.

\begin{tabular}{cccccccc}
\hline $\begin{array}{c}Z_{g} \\
(m)\end{array}$ & $\begin{array}{c}R \\
(m)\end{array}$ & $\begin{array}{c}h \\
(m)\end{array}$ & $\begin{array}{c}\alpha \\
(\mathrm{rad})\end{array}$ & $\begin{array}{c}\rho(\mathrm{kg} / \\
\left.\mathrm{m}^{3}\right)\end{array}$ & $\begin{array}{c}I_{0} \\
\left(\mathrm{kgm}^{2}\right)\end{array}$ & $\begin{array}{c}K_{\text {compr }} \\
\left(\mathrm{N} / \mathrm{m}^{2}\right)\end{array}$ & $\mathrm{K}_{t, 1}^{\prime}\left(\mathrm{N} / \mathrm{m}^{2}\right)$ \\
\hline 4.550 & 4.56 & 9.10 & 0.071 & 2038.73 & $\begin{array}{c}2.7 \mathrm{E}+0 \\
6\end{array}$ & $2.79 \mathrm{E}+8$ & $1.26 \mathrm{E}+7$ \\
\hline
\end{tabular}




\subsection{DMEM analyses}

The DMEM analyses have been performed by using the software HiStrA (Historical Structures Analysis) [29] in which the macro-model has been implemented. The free-standing façade condition (IS DME model) has been also investigated and shown in Figure 1b. The latter is composed of 288 shear-deformable elements, 4 rigid triangular elements, 757 interfaces and possesses 2040 degrees of freedom. In order to avoid hysteretic dissipation and makes the model comparable to the rigid body based strategy, simplified elastic linear softening constitutive laws have been employed in the analyses, calibrated according to the masonry parameters reported in Table 2: Mechanical masonry parameters adopted in the analyses.. The maximum in plane $(\lambda)$ and out-of-plane $\left(\lambda_{t}\right)$ distances between the transversal Links of the interfaces are set respectively equal to $20 \mathrm{~cm}$ and $10 \mathrm{~cm}$. The analyses have been performed assuming the hypothesis of small deformations and small displacements. The equations of motion have been integrated by means of an iterative Newmark algorithm [30] using the coefficients $\alpha=0.5$ and $\gamma=0.25$. The initial linear elastic dynamic properties of the free standing façade have been investigated in terms of frequencies and vibration modes, Figure 6 . The corresponding vibration periods $(T)$ and effective masses $\left(M_{e f f}\right)$ are reported in Table 5: Modal characterization of the DMEM mode.for two different values of elastic modulus: $E=1500 \mathrm{Mpa}$ and a ten-times higher modulus $\mathrm{E}=15000 \mathrm{MPa}$ in order to obtain a condition similar to those provided by the $R R$ model. The latter model has periods of vibration about three times lower, which is in effect coherent with the fact that the circular frequency is proportional to the square of the stiffness, linear function of the elastic modulus.

Table 5: Modal characterization of the DMEM mode.

\begin{tabular}{lcccccc}
\hline \multirow{2}{*}{ Model } & \multicolumn{2}{c}{ First mode } & \multicolumn{2}{c}{ Second mode } & \multicolumn{2}{c}{ Third mode } \\
& Period (s) & $\mathrm{M}_{\text {eff }}(\%)$ & Period (s) & M eff $^{(\%)}$ & Period (s) & M eff $_{\text {er }}$ \\
\hline $\mathrm{E}=1500 \mathrm{MPa}$ & 0.955 & \multirow{2}{*}{60.96} & 0.378 & 0 & 0.169 & \multirow{2}{*}{38.65} \\
$\mathrm{E}=15000 \mathrm{MPa}$ & 0.302 & & 0.120 & & 0.054 & \\
\hline
\end{tabular}

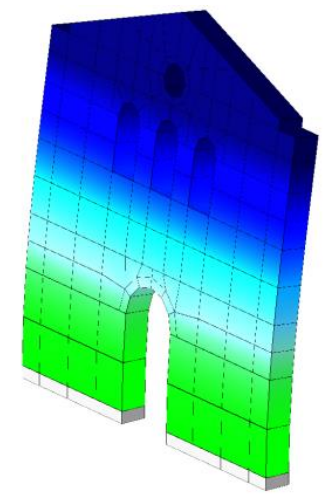

First mode



Second mode

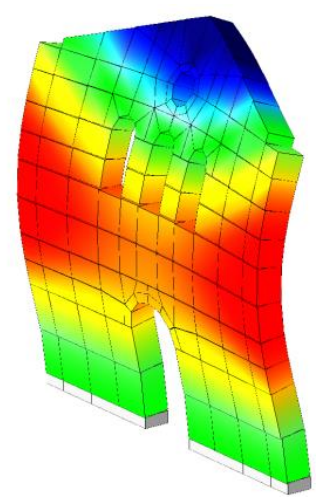

Third mode

Figure 6: Modes of vibration of the HISTRA DMEM model (E=1500 MPa).

\section{THE NONLINEAR TIME HISTORY ANALYSES}

The non-linear dynamic analyses have been performed employing the $R R$ and $D M E$ models, considering the influence of the masonry deformability as well as a damping contribution. The previously introduced two values of Young modulus $\left(E_{1}=1500 \mathrm{Mpa}\right.$ and $\left.E_{2}=15000 \mathrm{Mpa}\right)$ have been assumed as representative of the effective masonry deformability and of an almost rigid facade. In the DME model the damping effects has been introduced according to a mass and 
stiffness (Ray-damp) and only stiffness proportional (K-damp) damping matrix. The equivalence with the damping introduced by the $R R$ model have been considered by applying Eq. (6). The corresponding values of the damping ratios and the $a_{0}$ and $a_{1}$ parameters, proportional to the stiffness and mass matrices, are reported in Table 6.

Figure 7 reports the deformed shapes of the DME model, corresponding to the peak-displacement of each considered earthquake, while Figure 8 shows the deformation shapes at the maximum, positive and negative displacement of the DME model in presence of the transversal walls (2S DME model) for the T1213 earthquake. The time-histories of the DME models are reported in the following and referred to the top section of the tympanum for the $2 S$ model and the top section of tympanum and the top corner façade for the $S 1$ model.

Table 6: Viscous damping factors.

\begin{tabular}{ccccccc}
\hline & $\xi$ & $\omega_{1}$ & $\omega_{2}$ & \multicolumn{2}{c}{ Rayleigh } & K proportional \\
& $(\%)$ & $(\mathrm{rad} / \mathrm{s})$ & $(\mathrm{rad} / \mathrm{s})$ & $a_{0}$ & $a_{1}$ & $a_{0}$ \\
\hline $\mathrm{E}=1500 \mathrm{MPa}$ & 1.9 & \multirow{2}{*}{6.579} & \multirow{2}{*}{16.622} & 0.1772 & 0.0016 & 0.0057 \\
& 3.6 & & & 0.3347 & 0.0031 & 0.0108 \\
$\mathrm{E}=15000 \mathrm{MPa}$ & 1.9 & \multirow{2}{*}{20.805} & \multirow{2}{*}{52.360} & 0.5598 & 0.0005 & 0.0018 \\
& 3.6 & & 1.0571 & 0.0010 & 0.0034 \\
\hline
\end{tabular}

\begin{tabular}{|c|}
\hline$\geq 0,000 \mathrm{~mm}$ \\
\hline$-21,667 \mathrm{~mm}$ \\
\hline$-43,333 \mathrm{~mm}$ \\
\hline$-65,000 \mathrm{~mm}$ \\
\hline$-86,667 \mathrm{~mm}$ \\
\hline$-108,333 \mathrm{~mm}$ \\
\hline$-130,000 \mathrm{~mm}$ \\
\hline$-151,667 \mathrm{~mm}$ \\
\hline$-173,333 \mathrm{~mm}$ \\
\hline$-195,000 \mathrm{~mm}$ \\
\hline$-216,667 \mathrm{~mm}$ \\
\hline$-238,333 \mathrm{~mm}$ \\
\hline \hline$\leq-260,000 \mathrm{~mm}$ \\
\hline
\end{tabular}

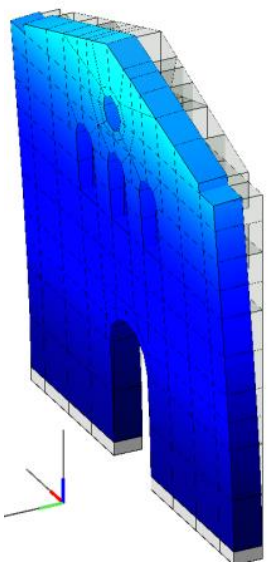

AMT - time 5.65s

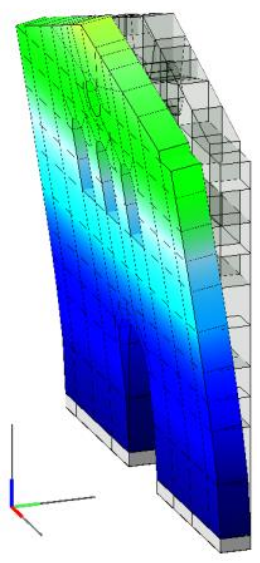

T1213 - time 2.90s



NOR - time 3.30s

Figure 7: Maximum deformations of the $2 S$ model - E=15000 MPa and Rayleigh damping 3.6\%.

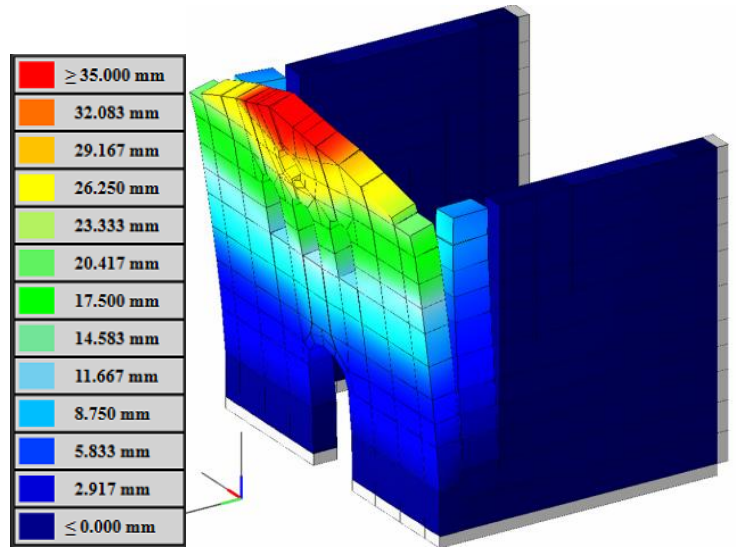

(a)

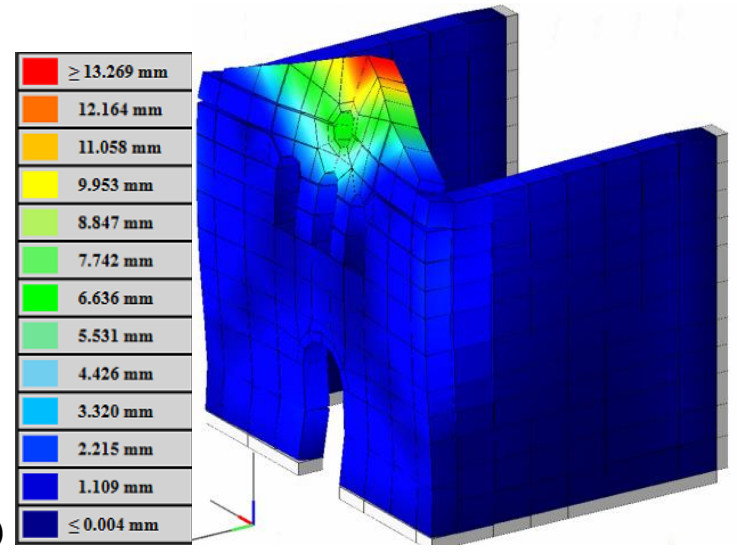

(b)

Figure 8: Maximum deformations of the $1 S$ model - E=15000 MPa, Rayleigh damping 3.6\% and T1213 signal. 
In the following two subsections the comparison between the RR and the DME models in the free standing and the constrained conditions are reported.

The results are expressed in terms of the out-plane drift of the wall $(\theta)$ normalized by its slenderness $(\alpha)$.

\subsection{Comparison between the RR and the DME models in the free standing condition}

In Figure 9 the time-histories of RR and DME models in the freestanding conditions $e=90 \%$ and the considered assumptions on damping are reported. The DME models show similar results for both the assumed viscous damping matrices. The comparison with the rigid block approach shows that the results corresponding to the RR models are generally characterized by larger rotations particularly for the NOR and T1213 accelerograms independently on the adopted elastic modulus. A better agreement between the RR and DME models can be observed at the beginning of the time-histories than the RR generally exhibits greater rotation amplitudes.

It should be observed that due to the high nonlinearity of the dynamic response it not possible to provide general conclusions with reference to few investigations. Furthermore, in the assumed RR model the dissipation is associated only to the impact conditions while in the DME approach the dissipation is expressed according to a viscous matrix. The deformability of the masonry walls, related to the elastic modulus in the DME models, lead to some differences in the time-histories analyses of the corresponding DME models but do not provide a better a substantially better agreement with the RR model. This can also be related to the small displacement hypothesis assumed for the DME models. However, in this case neither the RR models or the DME models show an overturning of the façade. Table 7 reports the results in terms of peak rotations.

In the case of lower energy dissipation, Figure 10, corresponding to $e=95 \% e_{a n}$ and $\xi=$ $1.9 \%$, the RR models exhibit overturning of the façade for the earthquakes with highest PGV and PGV/PGA values (NOR and T1213). However, all the DME models do not show rotation values corresponding to the condition of overturning although the displacement amplitude of DME models are very close to the critical rotation, corresponding to the rotation according to which the gravity loads do not contribute to the stability of the façade.

\subsection{Comparison between the RR and the DME models in the restrained condition}

Figure 11 reports the time-histories of RR and DME models in the restrained conditions corresponding to the value of the restitution coefficient $e=90 \%$ and the corresponding value of Rayleigh damping $(\xi=3.6 \%)$ subjected to the AMT and T1213 accelerograms. The rigid block rotation is compared to the values of the two monitored target point of the façade corresponding to the top of the tympanum and the corner point, in order to highlight the effect of the spatial response of the DME model. The results show a different time history between the rigid body simulation and the DME model however in this case a better agreement can be observed in terms of maximum rotations. The results in terms of normalized rotations are rather similar in the two cases (Table 8), with the only exception of NOR earthquake, which is characterized by the lowest value of PGA and lower frequencies (Figure 5) among those selected.

The DME seems to be slightly more conservative, assuming the top of the corner as control point. In this case the $R R$ shows maximum normalized rotations of approximately 0.03 which corresponds to a maximum horizontal displacement of about $2 \mathrm{~cm}$. With regard to the DMEM response, the peak displacements of tympanum assumed as control point resulted from $29 \%$ (NOR) to 43\% (T1213) greater than the peaks at the corner. This clearly denotes the formation of a 2-way bending mechanism within the façade, even in presence of wake lateral connections. 


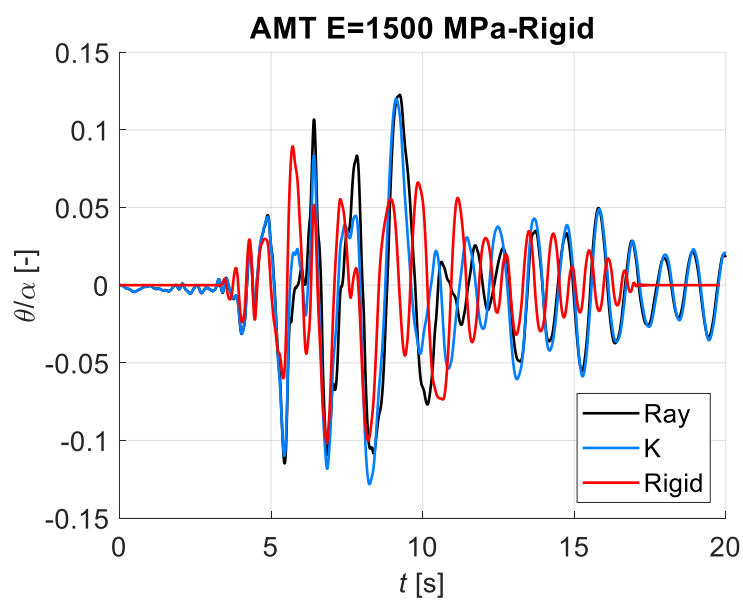

(a)

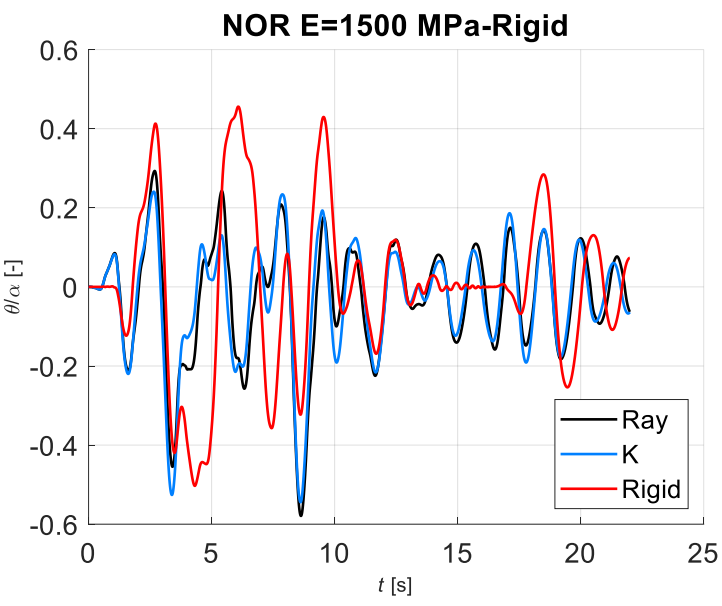

(c)

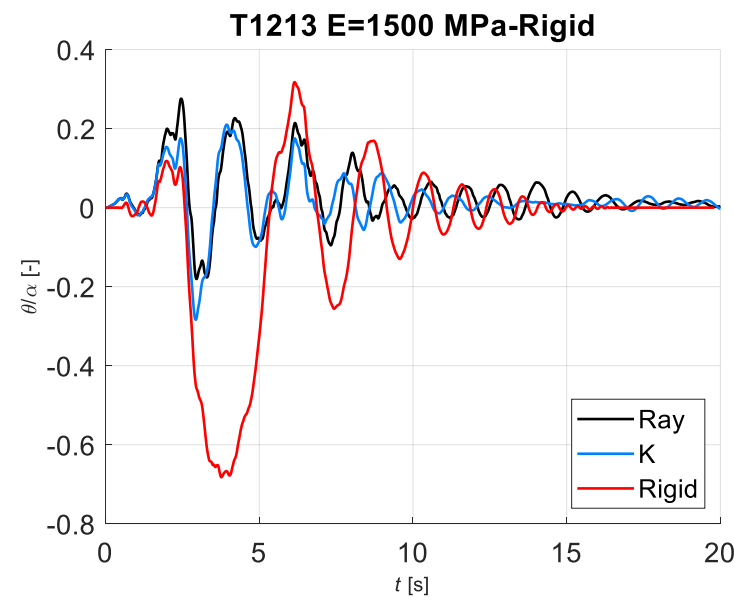

(e)

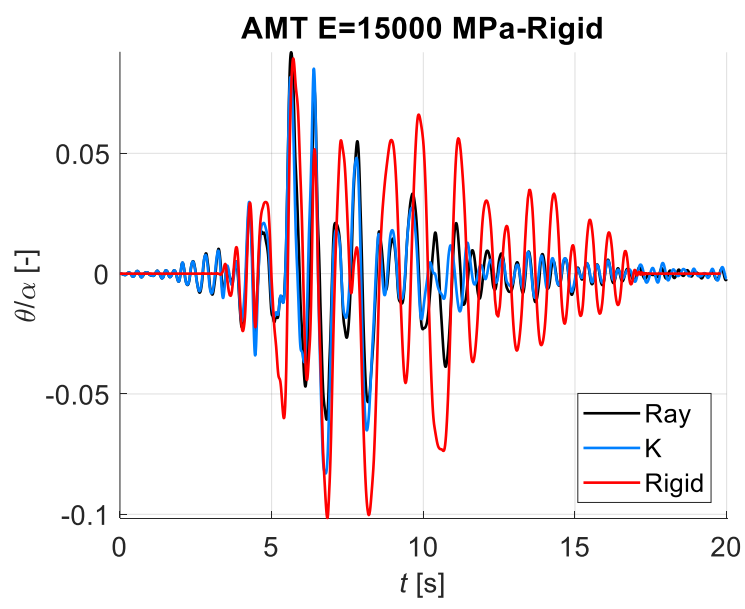

(b)

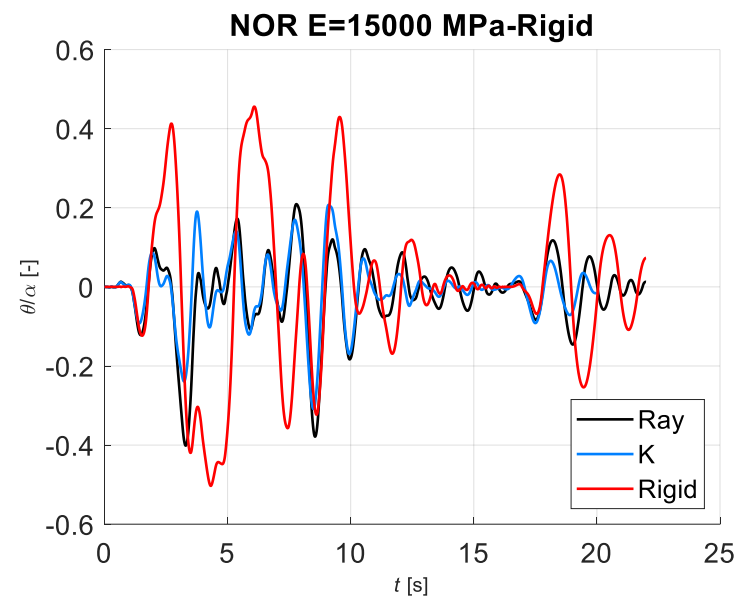

(d)

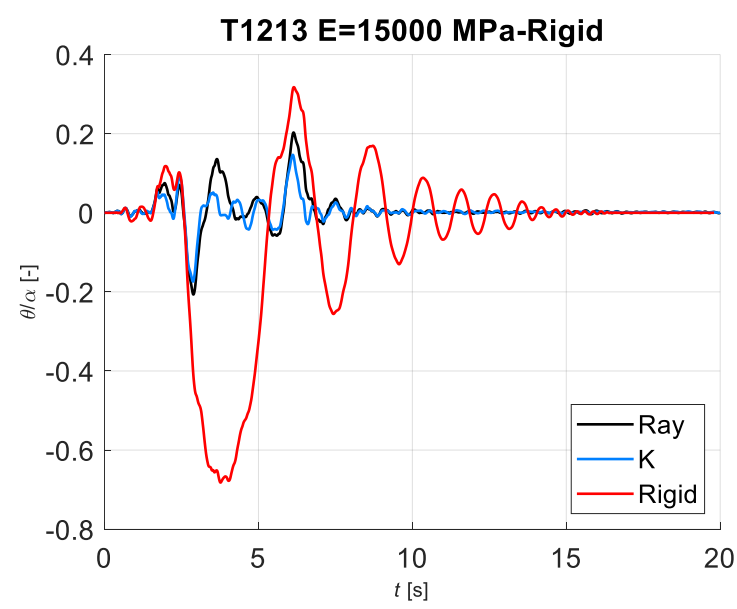

(f)

Figure 9: Comparison of results for $e=90 \% e_{a n}(\xi=3.6 \%)$. 


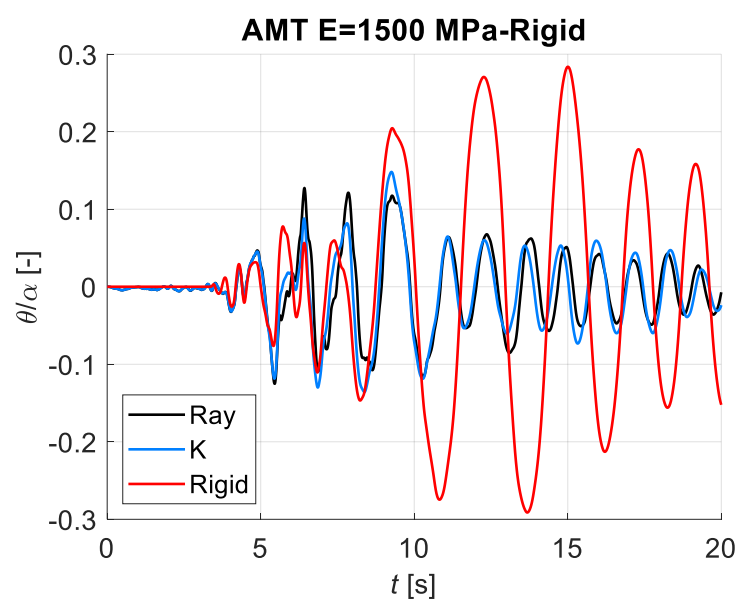

(a)

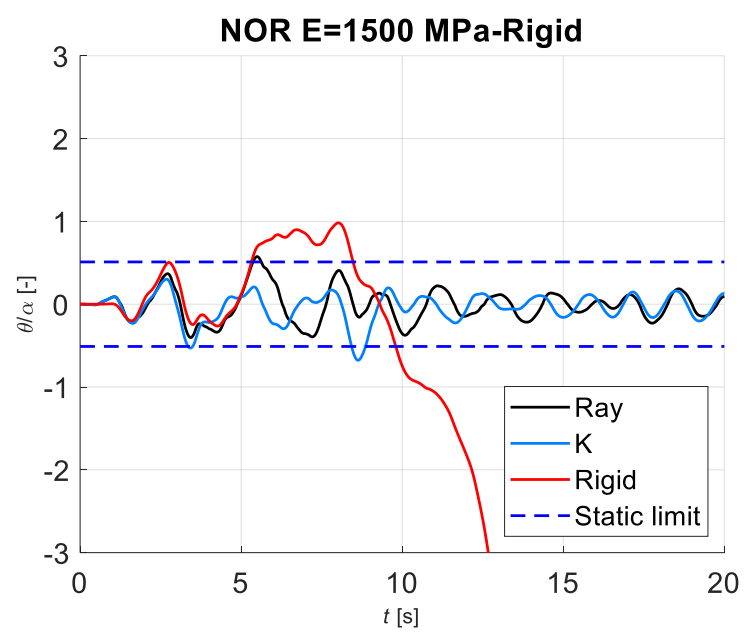

(c)

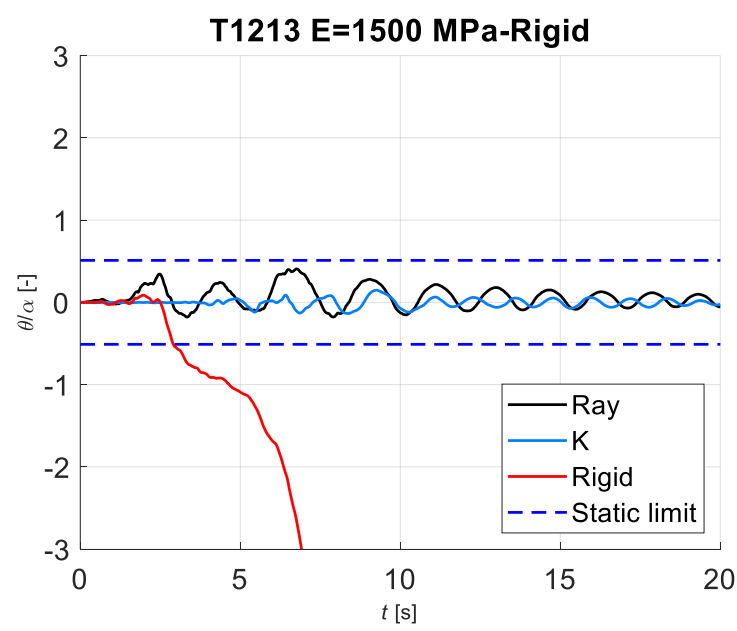

(e)



(b)

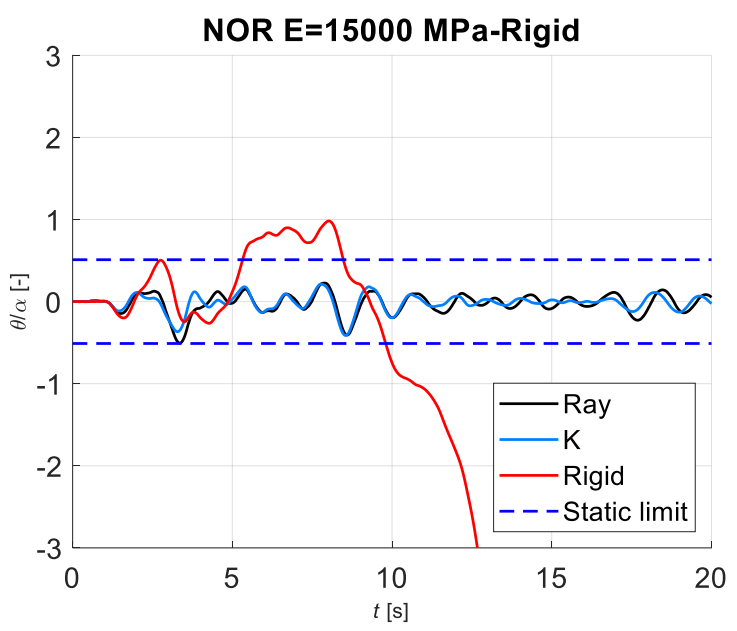

(d)

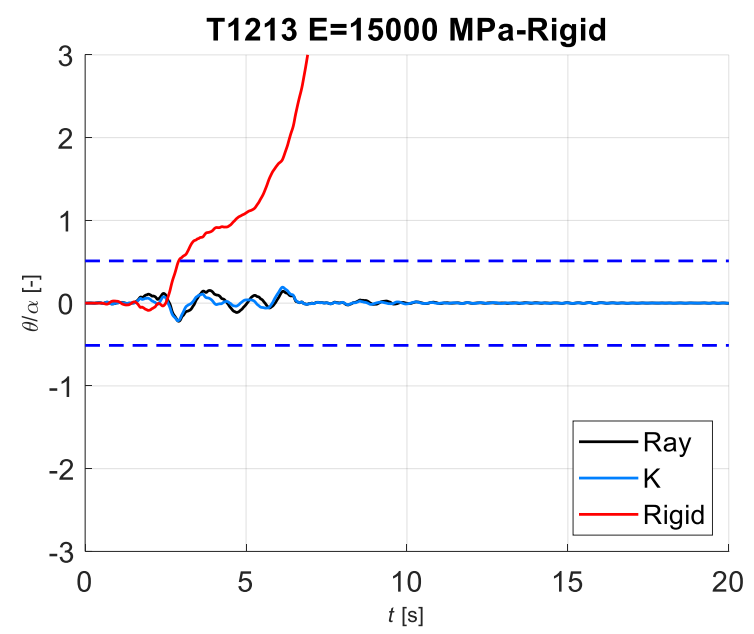

(f)

Figure 10: Comparison of results for $e=95 \% e_{a n}(\xi=1.9 \%)$. 
Table 7: Maximum normalized rotation amplitude $-e=0.95 e_{a n}-\xi=1.9 \%$.

\begin{tabular}{lccccc}
\hline & \multicolumn{3}{c}{ DMEM } & Rigid Block \\
& E1-Ray & E1-K & E2-Ray & E2-K & \\
\hline T1213 & 0.4064 & 0.1481 & 0.2185 & 0.2123 & Overturning \\
NOR & 0.5746 & 0.6764 & 0.5045 & 0.4122 & Overturning \\
AMT & 0.1273 & 0.1481 & 0.1005 & 0.0958 & 0.2912 \\
\hline
\end{tabular}

Table 8: 1S-models: maximum normalized rotation amplitude $-e=0.90 e_{a n}-\xi=3.6 \%$.

\begin{tabular}{lccc}
\hline & \multicolumn{2}{c}{ DMEM } & RR (Rigid Block) \\
& Tympanum & Corner & $\mathrm{K}_{t, 1}^{\prime}$ \\
\hline T1213 & 0.054 & 0.031 & 0.027 \\
NOR & 0.048 & 0.034 & 0.010 \\
AMT & 0.032 & 0.021 & 0.020 \\
\hline
\end{tabular}

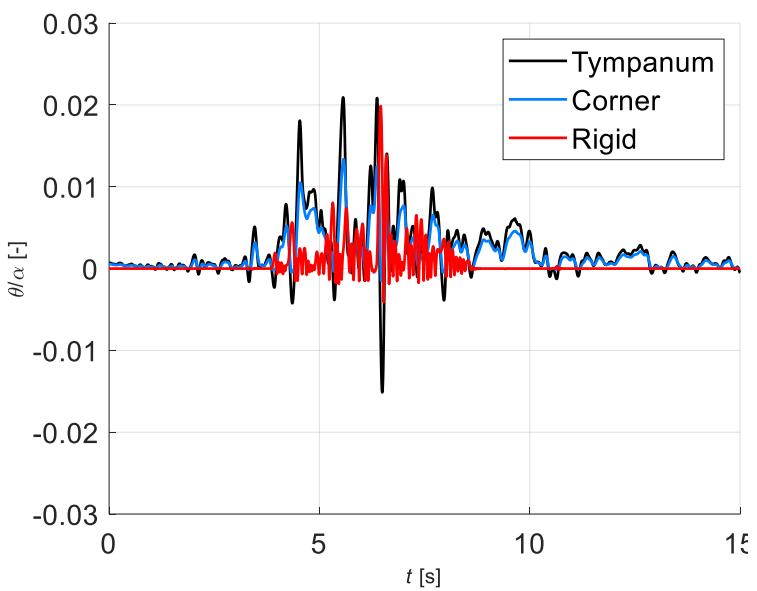

(a)

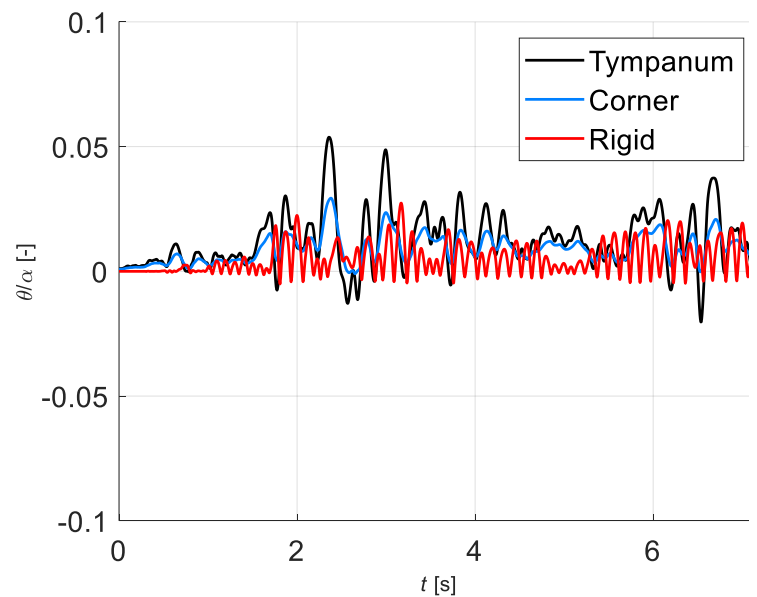

(b)

Figure 11: Comparison of results for $1 \mathrm{~S}$-models with $\mathrm{K}_{t, 1}^{\prime}$ and $e=90 \% e_{a n}(\xi=3.6 \%)$ : AMT (a); T1213 (b).

\section{CONCLUSIONS}

This paper investigates the out-of-plane response of masonry façades under earthquakes by means of two different approaches. A discrete macro-element approach, based on modelling the structure by means of spatial deformable macro-elements interacting through nonlinear zero-thickness interfaces, and the classical approach in which the masonry façade is assumed as a rigid block subjected to earthquake loading. The condition of free standing façade and unilateral constrained façade have been investigated for both models. The results of dynamic non-linear analyses, performed with the two methods on a real case of a church façade, provide a first comparison between the two approaches, highlighting some limits of applications of the simplified rigid block model.

The comparison between the two models, although requiring further investigations, seems to suggest that the free standing model does not adequately represent the nonlinear dynamic response of masonry facades. A better agreement can be obtained by considering a unilateral restrained rigid block; however, also in this case the masonry deformability significantly modifies the time-history responses. 


\section{REFERENCES}

[1] V. Alecci and M. De Stefano, Building irregularity issues and architectural design in seismic areas, Frattura e Integrità Strutturale 13(47), 2019, 161-168.

[2] V. Alecci, M. De Stefano, S. Galassi, M. Lapi, M. Orlando, Evaluation of the American Approach for Detecting Plan Irregularity, Advances in Civil Engineering 2019, 2019, Article number 2861093.

[3] S. Caddemi, I. Caliò, F. Cannizzaro, B. Pantò, New Frontiers on seismic Modeling of Masonry structures. Frontiers in Built Environment, 3-39,2017. https://doi.org/10.3389/fbuil.2017.00039.

[4] L. Sorrentino, D. D’Ayala, G. de Felice, M.C. Griffith, S. Lagomarsino, G. Magenes, Review of out-of-plane seismic assessment techniques applied to existing masonry buildings. International Journal of Architectural Heritage, 11(1), 2-21, 2017.

[5] J. Heyman, The Masonry Arch (Ellis Horwood series in engineering science), Ellis Horwood Ltd, 1990.

[6] M. Andreini, A. De Falco, L. Giresini, M. Sassu, Collapse of the historic city walls of Pistoia (Italy): causes and possible interventions. In: Adv. in Civil Structures. App. Mech. and Mat., 352, 1389-1392, Trans Tech Publication, ISBN: 9783037857748,ISSN:16627482, doi:10.4028/www.scientific.net/AMM.351-352.1389.

[7] C. Casapulla, L. Giresini, M. Sassu, P.B. Lourenço, Rocking and kinematic approaches of masonry walls: state of the art and recent developments. Buildings, 2017.

[8] I. Caliò, M. Marletta, B. Pantò, A new discrete element model for the evaluation of the seismic behaviour of unreinforced masonry buildings. Engineering Structures, 40, 327 338, 2012.

[9] B. Pantò, F. Cannizzaro, I. Caliò, P.B. Lourenço, Numerical and experimental validation of a 3D macro-model for the in-plane and out-of-plane behavior of unreinforced masonry walls. Int. Journal of Architectural Heritage, 11(7), 946-964, 2017.

[10] C. Chácara, P.B. Lourenço, B. Pantò, F. Cannizzaro, I. Caliò, Parametric numerical studies on the dynamic response of unreinforced masonry structures. In Structural Analysis of Historical Constructions: Anamnesis, Diagnosis, Therapy, Controls: Proc. 10th SAHC Conference, CRC Press 2016, Leuven, Belgium, 13-15 September, p. 239.

[11] C. Chácara, Macro-element nonlinear dynamic analysis for the assessment of the seismic vulnerability of masonry structures (Doctoral dissertation, Universidade do Minho), 2018.

[12] C. Chácara, F. Cannizzaro, B. Pantò, I. Caliò, P.B. Lourenço, Assessment of the dynamic response of unreinforced masonry structures using a macroelement modeling approach. Earthquake Engineering \& Structural Dynamics, 47(12), 2426-2446, 2018.

[13] F. Cannizzaro, P.B. Lourenço, Simulation of shake table tests on out-of-plane masonry buildings. Part (VI): discrete element approach. International Journal of Architectural Heritage, 11(1), 125-142, 2017.

[14] G.W. Housner, The behavior of inverted pendulum structures during earthquakes. Bulletin of the Seismological Society of America, 53, 403-417, 1963. 
[15] L. Sorrentino, O. AlShawa, L.D. Decanini, The relevance of energy damping in unreinforced masonry rocking mechanisms. Experimental and analytic investigations. Bull. Earthq. Eng., 9(5), 1617-1642, 2011.

[16] L. Giresini, M. Sassu, L. Sorrentino, In situ free - vibration tests on unrestrained and restrained rocking masonry walls. Earthquake Engng Struct Dyn, (1)20, 2018, https://doi.org/10.1002/eqe.3119.

[17] I. Caliò, M. Marletta, B. Pantò, A discrete element approach for the evaluation of the seismic response of masonry buildings. 14th World Conference of Earthquake Engineering (pp. 1-8), 2008.

[18] S. Caddemi, I. Caliò, F. Cannizzaro, G. Occhipinti, B. Pantò, A Parsimonious Discrete Model for the Seismic Assessment of Monumental Structures, J. Kruis, Y. Tsompanakis, B.H.V. Topping eds. Fifteenth International Conference on Civil, Structural and Environmental Engineering Computing, Civil-Comp Press, Stirlingshire, UK, Paper 82, 2015. doi:10.4203/ccp.108.82

[19] F. Cannizzaro, B. Pantò, S. Caddemi, I. Caliò, A Discrete Macro-Element Method (DMEM) for the nonlinear structural assessment of masonry arches. Engineering Structures, 168, 243-256, 2018.

[20] B. Pantò, F. Cannizzaro, S. Caddemi, I. Caliò, 3D macro-element modelling approach for seismic assessment of historical masonry churches. Advances in Engineering Software, 97, 40-59, 2016.

[21] B. Pantò, L. Giresini, M. Sassu, I. Caliò, Non-linear modeling of masonry churches through a discrete macro-element approach. Earth. and Struct., 12(2), 223-236, 2017.

[22] L. Giresini, C. Casapulla, R. Denysiuk, J. Matos, M. Sassu, Fragility curves for free and restrained rocking masonry façades in one-sided motion, Engineering Structures, 164, 195-213, 2018, doi: 10.1016/j.engstruct.2018.03.003.

[23] A. De Falco, L. Giresini, M. Sassu, Temporary preventive seismic reinforcements on historic churches: numerical modeling of San Frediano in Pisa. Applied Mechanics and Materials, 352, 1393-1396, Trans Tech Publication, ISBN: 9783037857748, ISSN:13931396, 2013, doi:10.4028/www.scientific.net/AMM.351-352.1393.

[24] C. Casapulla, L. Giresini, L.U. Argiento, S. Lagomarsino, Incremental Static and Dynamic Analyses of the Out-of-Plane Response of a Masonry Church damaged by 20162017 Central Italy Earthquakes, ANIDIS 2017, ISBN 978-886741-8541 ISSN 2532-120X, At Pistoia, 2017.

[25] NTC 2018, Italian Ministry of Infrastructure, D.M. 2018. Aggiornamento delle «Norme tecniche per le costruzioni, GU Serie Generale n.42 del 20-02-2018 - Suppl. Ord. n. 8

[26] C. Casapulla, L. Giresini, Non-Linear Static And Dynamic Analysis Of Rocking Masonry Corners Using Rigid Macro-Block Modelling, submitted, 2019.

[27] C. Casapulla, A. Maione, L. U. Argiento, E. Speranza, Corner failure in masonry buildings: An updated macro-modeling approach with frictional resistances. European Journal of Mechanics-A/Solids, 70, 213-225, 2018.

[28] C. Casapulla, A. Maione, Experimental and analytical investigation on the corner failure in masonry buildings. Interaction between rocking-sliding and horizontal flexure. International Journal of Architectural Heritage, 1-13, 2018. 
[29] HiStrA (Historical Structure Analysis). HISTRA s.r.l, Catania, Italy. Release 5.1.7, January 2018 (www.grupposismica.it).

[30] K.J. Bathe, E.L. Wilson, Numerical methods in finite element analysis, Prentice-Hall, Englewood Cliffs, N. J., 1976.

[31] K.J. Bathe, Finite element procedures. Klaus-Jurgen Bathe, 2006. 